\section{Instant messaging reference: users' evaluation of library chat}

\author{
Margie Ruppel and \\ Fody Condit Fagan
}

\section{The authors}

Margie Ruppel is Assistant Professor and Undergraduate Librarian and Jody Condit Fagan is Assistant Professor and Sociai Sciences Librarian, both at Morris Library, Southern Illinois University, Carbondale, Illinois, USA.

\section{Keywords}

Reference libraries, Academic libraries, Library users, Evaluation, Internet

\section{Abstract}

This article analyzes survey results of university students who used Morris Messenger, the instant messaging (IM) reference service at Southern Illinois University Carbondale's Morris Library. It focuses on the complete results of two surveys, including a comparison of IM reference and traditional reference desk experiences. An overview of the $I \mathrm{M}$ reference system and usage data are also discussed. Survey respondents indicated overall enthusiasm for the $\mathrm{IM}$ reference service and provided useful suggestions for improvements, which are also listed.

\section{Electronic access}

The research register for this journal is available at http://www.emeraldinsight.com/researchregisters

The current issue and full text archive of this journal is available at http://www.emeraldinsight.com/0090-7324.htm

Reference Services Review

Volume $30 \cdot$ Number $3 \cdot 2002 \cdot$ pp. 183-197

c. MCB UP Limited ISSN 0090-7324

DO1 $10.1108 / 00907320210435464$

\section{Introduction}

Instant messaging (IM) has established itself as a popular communication medium, particularly among teenagers. One-fifth of Americans and 74 percent of the 18 million online teenagers use IM on at least a weekly basis (Whelen, 2001).

Given that the next generation of college students often chooses to use IM rather than pick up the phone or go see their friends in person, libraries that learn to use this medium will be positioned to meet more successfully the challenge of providing reference services in an increasingly digital world.

Providing innovative library services requires staff evaluation and user assessment. A point listed in the "Facets of quality for digital reference services" states:

Digital reference services should regularly evaluate their processes and services. Ongoing review and assessment help ensure quality, efficiency, and reliability of transactions as well as overall user satisfaction (Virtual Reference Desk Project, 2000).

The purpose of this study is to evaluate users' feedback, received in the form of two surveys. The findings will be useful to librarians in improving instant messaging reference services and will contribute to the growing literature on evaluating IM reference from the user's perspective. The data reveal the respondents' evaluation of this new reference service, as well as traditional reference service. A total of 392 surveys were collected and analyzed for this study.

Other research projects at Morris Library include analyses of the conversations themselves (Desai and Fagan, 2002); a comparison with Morris Library's Web site search (Fagan et al., 2001); a presentation of the overall system with helpful hints (Calloway et al., 2001); a study of the staff perceptions and experiences in offering the service; and an investigation of user behavior in the library's online environment (both in progress). An article describing the software created, Morris Messenger, was recently published in Information Technology and Libraries (Fagan and Calloway, 2001).

\section{Usage data and overview of the instant messaging (IM) reference service}

IM reference at Morris Library began as a pilot project in Summer 2001. At first, librarians 
staffed the service Monday-Friday from 1 p.m. to 4 p.m. During fall 2001, a few library reference assistants joined the group, and we added evening hours one day a week (Monday 6 p.m. to 9 p.m.). In spring 2002, we continued the Monday-Friday 1 p.m. to 4 p.m. schedule, and expanded evening hours to TuesdayThursday 7 p.m. to 9 p.m.

Morris Library uses software developed in-house called Morris Messenger. IM clients like ICQ and AOL were considered, but the library staff did not want patrons to have to install software. Morris Messenger is a browser-based instant messenger that uses Perl, MySQL, and a tiny bit of JavaScript. It accepts input from both staff and patron browsers, saves it into a MySQL database, and then displays the input to the other's client. The only lag time in the program is the browser's refresh rate; new lines of the conversation are not displayed until the browser refreshes, which happens about every 15 seconds.

The staff side of Morris Messenger (Figure 1) allows staff to:

- send messages to patrons;

- communicate with other online staff;

- redirect conversations to other online staff;

- send active URLs to patrons;

- push the patron's browser; and

- send preformatted answers to patrons directly or paste preformatted answers into the input box for editing before they are sent.

Each staff member has his or her own preformatted answers, nicknames, and buttons.

The patron interface of Morris Messenger (Figure 2) basically just allows patrons to enter text. When they finish the conversation, they can display the transcript immediately for printing, saving, or e-mailing. They are also asked to fill out a short online survey, which we refer to as the "short survey" in this study. Because the system stores the data locally, the librarians are able to research conversations, post online surveys, and perform other tests relating to the system.

In the fall 2001 semester, IM reference received an average of 9.5 questions per day, or approximately three questions per hour between 1 p.m. and 4 p.m. The service was less busy in the evening, receiving approximately two questions per hour between 6 p.m. and 9 p.m, on Monday evening. Since only one staff member could be online at a time, an average of 4.6 patrons per day got "busy signals" indicating the online staff member was with another patron. A total of 64 percent of the conversations were from within the library building; 35 percent originated outside the library but on the campus network, for example, in computer labs or dorms. Since the system's pages do not show online reference to off-campus users, only 1 percent of the usage comes from out-of-network patrons, who must manually type in a URL to access the service or find the input box on Morris Library's distance learning Web site.

\section{Literature review}

The initial goal in the literature review was to find articles that discussed similar studies of both IM and traditional reference service, namely the advantages and disadvantages of each, as reported from the view of the user. Finding such articles about traditional reference proved easy, but finding articles about user assessment of IM or chat reference was more difficult. IM reference is being studied, but user assessment studies of it are not yet abundant in the literature. This article and literature review is limited to sources that include studies of user assessment of reference, both IM and traditional. A sample of the literature published on users' evaluations of e-mail reference is also included. The authors used three methods of research for this article:

(1) library literature and information science sources;

(2) following up on secondary references included in other articles; and

(3) consulting citations listed in the "Digital reference services bibliography" (Sloan, 2002).

User assessment is just one slice of the evaluation "pie" and this fact is mentioned in the Association of Research Libraries' (ARL) SPEC Kit on Electronic Reference Service. It states: 
Figure 1 The staff side of Morris Messenger

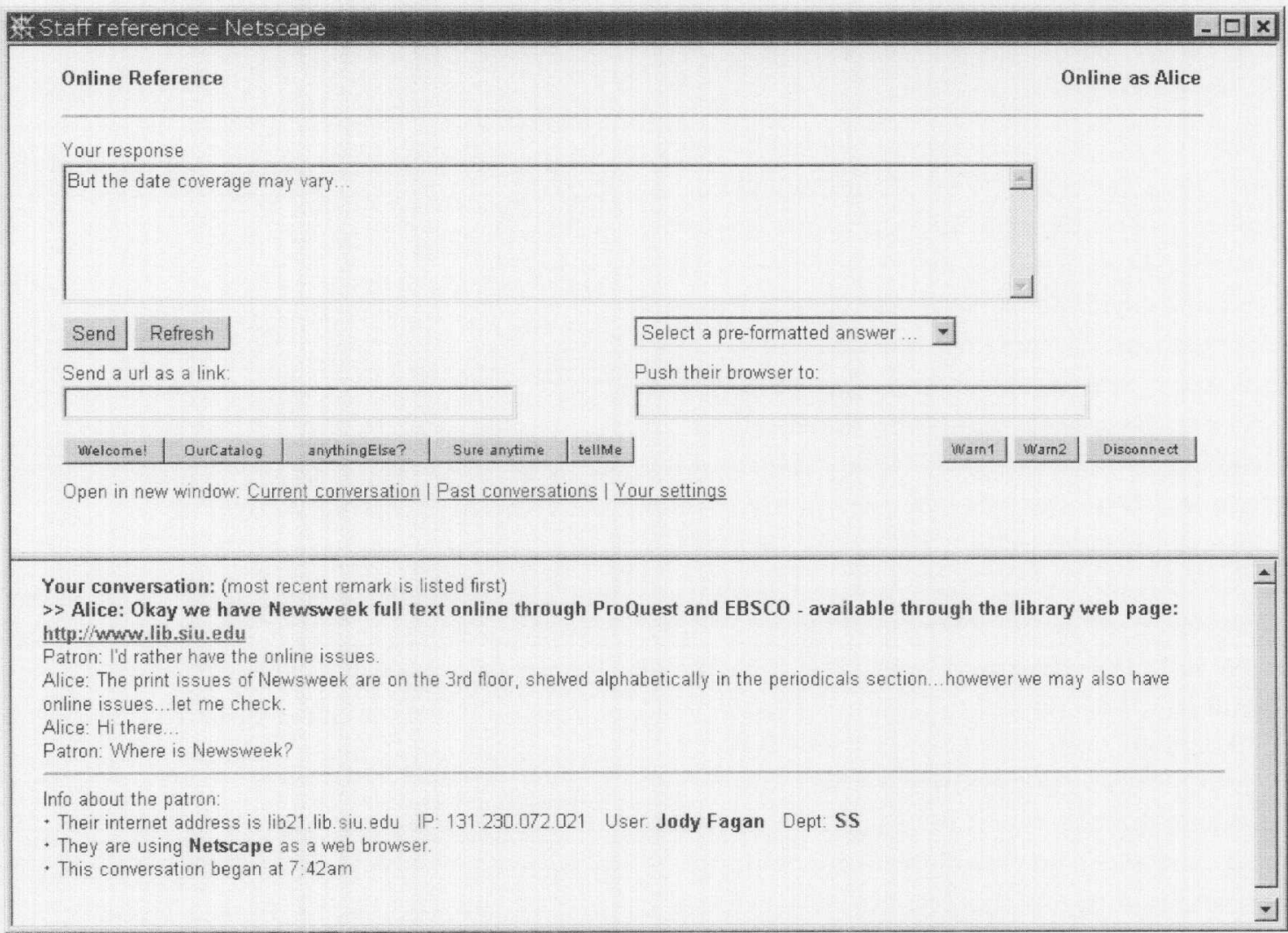

Figure 2 The patron side of Morris Messenger

Q7. Morris Library Orline Reference - Netscape
Morris LIBRARY
Online Reference
A Follow-up message?
Okay thanks for your help!
When using our online reference, please:
+ Dont press the Esc key or your connection will close.
+ You can print or email a copy of your conversation after you disconnect.
You are connected. The conversation is shown below with the most recent remark listed first.
$\rightarrow$ Alice: Okay we have Newsweek full text online through ProQuest and EBSCO - available
through the library web page: http://www.lib.siu.edu
You: I'd rather have the online issues.
Alice: The print issues of Newsweek are on the 3rd floor, shelved alphabetically in the periodicals
section...however we may also have online issues...let me check.
Alice: Hi there...
You: Where is Newsweek?


Instant messaging reference: users' evaluation of library chat Margle Ruppel and Jody Condit Fagan

Only 29 libraries (39 percent) are collecting user data. User information collected includes type of question; time of day; affiliation of patron; response; and number of questions rejected as being outside of scope or policy (Goetsch, 1999)

Only ten libraries ( 13 percent) had conducted user assessment surveys, both formal and informal, and the surveys were either "part of a general library user survey" or "follow-up at the end of individual transactions" (Goetsch, 1999). (Author' note: an updated SPEC kit on this topic is expected to be published in 2002.)

There have been numerous studies about user experiences at traditional reference desks; a sampling from the past three decades is discussed in this section. Although the studies all lament the lack of qualitative study on patron-librarians interpersonal relations, some clear common themes emerge from looking at them together.

Although not the first, Swope and Katzer's (1972) article, "Why don't they ask questions" is one of the key studies in this area. They found that 41 percent of their 119 respondents had questions about the library, but 65 percent of those would not ask for help (Swope and Katzer, 1972, p. 163). The major reasons the "non-askers" gave for not asking questions were (Swope and Katzer, 1972, p. 164):

- "Dissatisfied with past service".

- "The question was too simple for the librarian".

- "They didn't want to bother the librarian."

In 1977, Hernon and Pastine conducted a questionnaire study with 362 respondents concerning students 'perceptions of academic librarians. They found that many did not consider librarians to have "special educational background and subject expertise" (Hernon and Pastine, 1977, p. 133). Only 16 percent of their respondents "frequently" or "always" sought assistance immediately when searching (Hernon and Pastine, 1977, p. 134).

Difficulties with interpersonal relations stemmed from the following perceptions, which echo the findings of Swope and Katzer (Hernon and Pastine, 1977, p. 137):

- "Unwillingness to disturb or bother a busy librarian were numerous".

- "Preoccupied, rude, inconsiderate, and discourteous service".
Reference Services Review

volume $30 \cdot$ Number $3 \cdot 2002 \cdot 183-197$

- 'Did not want to appear 'stupid' or 'dumb' in front of others, and were often embarrassed by their ignorance ...."

Students wanted librarians to leave the desk and give assistance at the point of need, preferred informality and attentiveness, and wanted the librarian's complete attention.

The findings of Swope and Katzer and Hernon and Pastine were echoed in subsequent studies. In 1986, Hatchard and Toy's study of the psychological barriers existing between users and staff found "the usual" reasons given for negative feelings as given in the Swope and Katzer article. Their users also talked about not knowing what question to ask (Hatchard and Toy, 1986, p. 66). These themes stayed constant through 1994 (Dewdney and Ross, 1994), and were reiterated in Massey-Burzio's (1998) focus group study.

Clearly, for three decades, patrons have often chosen not to ask for help because they are or expect to be dissatisfied, embarrassed, or do not believe librarians are ready or willing to help them. Meanwhile, model reference behaviors keep suggesting answers without methods, to these problems: asking clarifying and follow-up questions, keeping patron informed of search progress, being friendly and at the same level as the patron to encourage approachability, etc. (Nelson, 1991). Other factors associated with "good" reference behaviors include being interested in the question, possessing very good listening skills, determining the need behind the question, using open questions effectively, and again, asking a follow-up question (Durrance, 1995; Ross and Dewdney, 1998). Will instant messaging be able to solve any of these problems and promote good reference behavior?

User reactions to IM reference have only been reported by a few institutions, but users seem initially positive. Librarians at the University of Illinois at Urbana-Champaign state:

Nearly 90 percent of the respondents reported the completeness of the answer to their question as very good or excellent. Nearly 85 percent found the service easy to use and would use it again (Kibbee et al., 2002).

The University of Buffalo reports the results of a short survey attached to each IM reference transaction:

Forty-five percent of respondents reported being very satisfied with the service. In fact, 79 percent declared 
Instant messaging reference: use's' evaluation of library chat Margie Ruppel and Jody Condit Fagan

themselves satisfied or better compared to 10 percent who registered some level of dissatisfaction. Most of the unhappy patrons had tried to access the service when it was closed (Foley, 2002)

Articles written about online reference mention both IM and e-mail. E-mail reference is most suited for brief research, such as factual types of information. A drawback of e-mail, however, is that although it is one-on-one, it is not a timely method; patrons do not always have a definite idea of when to expect a response. E-mail is not "instant," either, which is one often-cited advantage of IM reference. A sample of the literature on e-mail reference includes articles by Straw (2000) and Carter and Janes (2000).

\section{Methodology}

The authors designed two surveys to evaluate IM reference at Morris Library. The short survey (Figure 3) appears immediately after each patron disconnects from the service and poses three questions, plus an area to provide additional comments. Patrons may choose to complete the survey or close the window.

Answers to the survey are immediately
Reference Services Review

Volume $30 \cdot$ Number $3 \cdot 2002 \cdot 183-197$

submitted to the online staff member through the conversation screen. Questions ask how satisfied the patron is with the IM system, how satisfied they are with the answer they received, and whether or not they have used IM before. A total of 340 responses to the short survey are included in this study.

The "long survey" (see the Appendix) is a 15 question paper-format document that asks users to evaluate IM reference's effectiveness and compare it to traditional reference desk service. It was distributed to students enrolled in six sections of a library skills course (Curriculum \& Instruction 199 or CI 199) taught in both fall and spring semesters of the 2001-2002 academic year. CI 199, The Library as an Information Source, is a onecredit course taught by librarians at SIUC, usually with 30-40 students per section. The authors chose to distribute the long survey to this class because it represents various majors, classes (freshmen through senior), and experience with IM in general. In one section of CI 199,30 percent of the students were freshmen, 21 percent sophomores, 18 percent juniors and 30 percent seniors, while in another section of the course, 25 percent were freshmen, 13 percent sophomores, 31 percent

Figure 3 Screenshot of online survey

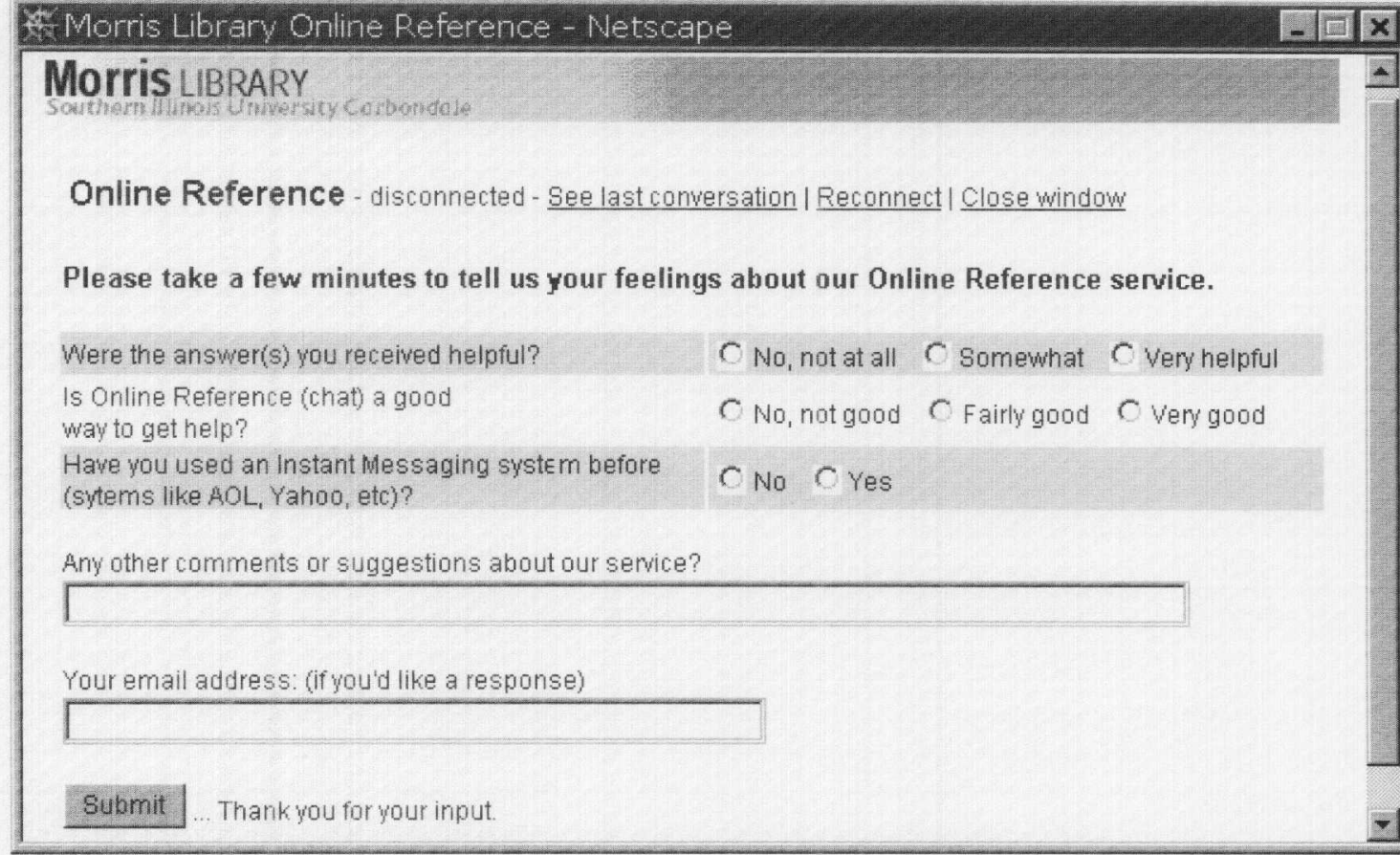


Instant messaging reference: users' evaluation of library chat Margie Ruppel and jody Condit Fagan

junior, and 31 percent seniors. In the first section, students' majors were in the science ( 6 percent), humanities ( 9 percent) and social science $(85$ percent) disciplines. A total of 52 completed long surveys are included in this study. Altogether, 392 people were surveyed for this project.

\section{Short survey results}

In response to the short survey, patrons were overwhelmingly positive about the service. Between June 7, 2001 and February 25, 2002, 340 people responded. Of these, 82 percent said IM reference is a "very" good method of getting help, while 7 percent said it was a fairly good method of getting help. A total of 82 percent said the answers they received were "very" helpful; 12 percent said the answers were "somewhat" helpful; 68 percent of the total respondents had used an IM service before (not necessarily for reference purposes).

Of the respondents, 115 left comments in the free-answer box. Table I attempts to break these responses down by category and offers the number of responses in each category for comparison purposes. If responses included several comments, each one was counted separately.

The most frequent type of comment on the short survey ( 33 of the 115 respondents) was a general acclamation of the service:

Table I Comments about Morris Messenger from the short survey

\begin{tabular}{|c|c|}
\hline An all around great job & 33 \\
\hline Helpful & 26 \\
\hline Fast & 12 \\
\hline Friendly/polite & 11 \\
\hline Thanks & 6 \\
\hline \multicolumn{2}{|l|}{ Knowledgeable/quality answer } \\
\hline $\begin{array}{l}\text { "Chris seemed very knowledgeable about the } \\
\text { questions I asked" }\end{array}$ & 4 \\
\hline \multicolumn{2}{|l|}{ Anonymity } \\
\hline $\begin{array}{l}\text { "Asking on the computer doesn't make one feel so } \\
\text { insecure, stupid, or afraid ..." }\end{array}$ & 3 \\
\hline \multicolumn{2}{|l|}{ Other } \\
\hline (included technical difficulties and specific & \\
\hline $\begin{array}{l}\text { suggestions such as "Have community calendars on } \\
\text { hand for the advisors") }\end{array}$ & $1-2$ each \\
\hline Total (respondents) & 115 \\
\hline
\end{tabular}

\author{
Reference Services Review \\ volume $30 \cdot$ Number $3 \cdot 2002 \cdot 183-197$
}

I think that this is a great service to the students. I will definitely use it again.

I am really impressed. Great idea. Someone should have thought of this a long time ago.

Of the respondents, 26 specifically mentioned "helpfulness," of both particular people and of the service in general ("Very helpful -

immediate is great!"); 12 mentioned the speed of the service ("Very pleasantly surprised about the speed and efficiency"); 11 mentioned friendliness or politeness, with comments such as:

The people on this service seem very friendly and cheerful.

Only three mentioned anonymity, which is surprising considering how commonly it was listed as an "advantage of IM" given by respondents to our long survey. See Table II for a summary of short survey results.

\section{Long survey results}

Most of the long survey respondents liked the IM reference system and say they would use it again in the future. On a scale of one to seven, with one indicating "loved it" and seven indicating "hated it," 69 percent rated it a one, two or three. When asked to rate the quality of help received from the online librarian, on a scale of one to seven, with one indicating "fantastic" and seven indicating "terrible," 86 percent rated it a one, two or three.

Respondents also think the system's speed is sufficient ( 90 percent) and that online staff respond quickly ( 85 percent). Almost everyone (90 percent) said they would use the IM reference system again. A total of 40 percent of the long survey respondents had previously used IM (not necessarily for reference purposes).

Another item on the long survey asked:

Was this service different from what you expected when you entered your question? If Yes, how? (Table III).

This question had 18 "Yes" responses that chose to comment. Reasons fall into two categories: the service was better ( 90 percent) and the service was worse (10 percent). The most frequent answers to this question were that it was faster and more helpful than the 
Table II Summary of short survey data

\begin{tabular}{lcllll}
\hline Question & $n$ & Answer & Answer & Answer \\
\hline $\begin{array}{l}\text { Were the answer(s) you received helpful? } \\
\begin{array}{l}\text { Is online reference (chat) a good way to get } \\
\text { help? }\end{array}\end{array}$ & 340 & No, not at all 22 & Somewhat 40 & Very helpful 278 \\
$\begin{array}{l}\text { Have you used an instant messaging system } \\
\text { before (systems like AOL, Yahoo, etc.)? }\end{array}$ & 337 & No, not good 17 & Fairly good 25 & Very good 278 \\
\hline
\end{tabular}

Table III Was this service different from what you expected when you entered your question? If Yes, how?

More helpful than anticipated

Faster than anticipated

Thought it was a search engine/e-mail

Easier than anticipated

Slower than anticipated

More personal than anticipated

Total (responses)

Total (respondents)

anticipated. Six respondents commented that it was faster, including a "fast response rate" and "they answered questions faster than I expected." Comments from the six respondents who mentioned helpfulness included:

More info on what I needed that I didn't ask for.

Much more specific than I thought it would be. I was referred to exact $W^{\prime}$ eb sites.

I expected the respondent to give a brief answer but she made my answer really clear, able to understand and worth the time.

A few respondents had misconceptions about the nature of the service; one said "I didn't know if it was just e-mail," while another said "I thought of it more as a search engine." While 81 percent of the respondents expected to be referred to answers found online such as Web sites or online journals, 92 percent said they want library staff to tell them about both print and online sources, as opposed to only online sources.

One section of the survey asked the respondents to list features they would add to the IM reference service (Table IV); it received 51 responses. A total of 16 responses to this question included increasing the number of hours of the service, with two respondents mentioning 24-hour access. An additional 11 responses mentioned having more staff on at once to reduce busy signals:

I would have more librarians online so that many students can use this resource at once.
Table IV What features would you add to this service? (List some)

More hours of service

Fine the way it is

More staff on at the same time

Other (requests for system features that are already in place)

Collaborative reference/wider access

Videoconferencing

Show connection is active/staff is working

Make it faster

Total (responses)

Total (respondents)

One respondent was nearly prescient, saying:

Maybe (and I'm thinking big here) there could be a BIG system where librarians all over the country are on at all times (except maybe 3:00 a.m.) and they give basic assistance. But this service is good right now.

The next most frequent response $(n=13)$ was that it was fine the way it is: "You don't want to add too much and make it a hassle and confusing," said one person.

When asked what days/hours would be the best times to have IM reference available (they were asked to circle up to three of the six choices), weekday evenings were the most popular ( 87 percent). Weekend afternoons ( 50 percent) and weekday afternoons (48 percent) were also popular. Weekend evenings (25 percent), weekday mornings (23 percent) and weekend mornings ( 14 percent) were the other three possible answers. Overall, evenings are more popular during the week, but on the weekends, afternoons are more favored.

The long survey also asked respondents to compare IM reference to traditional reference desk service with both open and closed-ended questions. One question asked:

How frequently do you ask for help at traditional library help desks in the library building?

On a scale of one to seven, with one indicating "all the time" and seven indicating "never," 
Instant messaging reference: users' evaluation of library chat Margie Ruppel and lody Condit Fagan

only 38 percent of respondents chose four or above. About half ( 54 percent) of the users chose five or six, and "never" was chosen by 8 percent. "All the time" was only chosen by 6 percent of the respondents.

When asked why they usually do not ask for help at traditional library help desks (multiple responses were allowed), 29 percent said it is because the person at the desk does not look like they want to help or they look too busy; 23 percent said they do not want to have to get up from the computer; 23 percent said they feel stupid for not knowing already; 17 percent said they do not want to bother going to the library building; and 10 percent said they do not think the person at the desk will know the answer.

Of the respondents 46 percent see no change in the number of questions they will ask at traditional library help desks now that they can get help through IM reference. More users $(33$ percent) indicated their use of the traditional desk would increase than those indicating their use would decrease (21 percent). Only 2 percent chose "one," indicating they would "ask lots more questions," while 6 percent chose "seven," indicating they would ask far less questions. See Tables V-VII for a summary of long survey data.

Respondents were also asked to list advantages and disadvantages for both $\mathrm{IM}$ and traditional desk reference. For each of these four lists, categories were created based on the similarity and number of responses. If a person included multiple comments, they are included in multiple categories. While some respondents

Table V Summary of long surveys - general

\begin{tabular}{|c|c|c|c|}
\hline Question & $n$ & Yes & No \\
\hline Have used IM before & 52 & 21 & 31 \\
\hline Think system's speed is sufficient & 52 & 47 & 5 \\
\hline Think library staff respond quickly & 52 & 44 & 8 \\
\hline Would use IM reference service again & 52 & 47 & 5 \\
\hline $\begin{array}{l}\text { Expect to get referred to answers } \\
\text { found online (e.g. Web sites, online }\end{array}$ & & & \\
\hline journals) & 52 & 42 & 10 \\
\hline $\begin{array}{l}\text { Want staff to tell them about just } \\
\text { online sources or both online and }\end{array}$ & & & \\
\hline print sources & 52 & 48 both & 4 only online \\
\hline Service was different than expected & 52 & 18 & 34 \\
\hline
\end{tabular}

\author{
Reference Services Review \\ Volume $30 \cdot$ Number $3 \cdot 2002 \cdot 183-197$
}

listed multiple responses, others listed none. The total responses and total comments are listed for each question. Tables VIII-XI show the complete summary, while the sections below include illustrative quotes. The number of responses was about 60 for both the advantages and disadvantages of IM, while there were only about 50 responses for both the advantages and disadvantages of traditional desk reference.

\section{Advantages of IM reference}

The number one advantage of IM reference, according to 28 of the 60 responses, was convenience, with most comments regarding not having to get up from the computer (Table VIII). A total of 11 respondents mentioned the advantage of anonymity, with frank comments such as "if a person feels dumb for asking, they aren't 'revealed" "and "you feel free and you are not shy cause you cannot see your helper." Ten mentioned the quickness of the service, with one respondent also noting "quick instructions are in writing so you can refer back to them." Six responses showed appreciation for the easiness of the service. Five responses indicated that they thought the quality of service was better with IM, with comments like "better suggestions from librarians - more specific" and "people seem more willing to help you out."

\section{Disadvantages of $I M$ reference}

Limited availability in terms of both hours of service and number of people online at the same time was first on the list, with 20 responses (see Table IX). One respondent said "It is a toss up as to whether you can get on if there are a lot of people using it," but most mentioned simply "more hours." A total of 12 responses mentioned the inability of online staff to show resources directly, including comments such as "can't physically show you something" and "they can't walk you to what you need." Eight responses mentioned some kind of inconvenience, with four mentioning computer access being a problem ("finding empty terminal"), and four mentioning that it was inconvenient to get help online and then not be able to "physically access the books and such that you want." Six mentioned slowness of response; it was not possible to tell if this was 
Table VI Summary of long surveys - Likert scale questions

\begin{tabular}{|c|c|c|c|c|c|c|c|c|c|c|}
\hline Question & $n$ & & 7 & 6 & 5 & 4 & 3 & 2 & 1 & \\
\hline \multicolumn{11}{|c|}{ Liked using the IM reference system as a way to get } \\
\hline help & 51 & Hated it & 2 & 1 & 3 & 10 & 11 & 10 & 14 & Loved it \\
\hline Quality of help received from online librarian & 51 & Terrible & 1 & 1 & 1 & 4 & 8 & 18 & 18 & Fantastic \\
\hline \multicolumn{11}{|c|}{ Frequency of asking for help at raditional library help } \\
\hline desks & 52 & Never & 4 & 12 & 16 & 7 & 8 & 2 & 3 & All the time \\
\hline $\begin{array}{l}\text { Increase/decrease in the number of questions } \\
\text { at traditional ibrary help desks now that the }\end{array}$ & & & & & & & & & & \\
\hline aware of IM reference service & 52 & Increase & 1 & 2 & 5 & 24 & 11 & 5 & 3 & Decrease \\
\hline
\end{tabular}

Table VII Reasons patrons do not usually ask for help at traditional library help desks and whether it would be an issue with IM reference

\begin{tabular}{|c|c|c|c|c|c|}
\hline Reason & $n$ & Yes & No & $\begin{array}{l}\text { Would not } \\
\text { be an issue }\end{array}$ & $\begin{array}{l}\text { Would be } \\
\text { an issue }\end{array}$ \\
\hline I do not want to get up from computer & 52 & 12 & 40 & & \\
\hline Person at desk does not look like they want to help or look too busy & 52 & 15 & 37 & & \\
\hline Person at desk will not know the answer & 52 & 5 & 47 & & \\
\hline I feel stupid for not knowing already & 52 & 12 & 40 & & \\
\hline I do not want to bother going to the library building & 52 & 9 & 43 & & \\
\hline
\end{tabular}

Table VIII Advantages of instant messaging

\begin{tabular}{lr}
\hline Convenience & 28 \\
Anonymity & 11 \\
Speed "it's quick" & 10 \\
Easy & 6 \\
Quality & 5 \\
Other & 1 \\
Total (responses) & 60 \\
Total (respondents who answered the question) & 51 \\
\hline
\end{tabular}

Table IX Disadvantages of instant messaging

Limited availability/limited staff online 20 Indirect (cannot be physically directed) Inconvenient

Slowness (staff and system)

Technical difficulties (potential and actual)

Impersonal

Poor quality of answers

Other

Total (responses)

Total (respondents)

attributed to the staff or the system, although one person went on to say that when it was slow, one "can't see if the person is really doing what they suppose to be doing." Six mentioned actual or possible technical difficulties ("computers crash, they're not 100 percent dependable"). Only three responses mentioned "impersonal" service, which is surprising since face-to-face interaction was mentioned frequently as a great advantage of the traditional desk. Other interesting comments in this category included one complete misunderstanding of the human behind the service (or the poor performance of the online staff member): "if you don't phrase the question correctly the computer may misinterpret you," and the only comment in this study about the multi-threaded nature of IM: "just as with any IM, sometimes people talk at the same time. This is well worth it though."

\section{Advantages of traditional reference desk}

The most frequent response in this category was the personal touch received at a traditional reference desk (see Table X). A total of 23 responses echoed the sentiment that "it's always nice to talk and see a real person," with eight responses using the phrase "face to face" and four using either the phrase "one on one" or "person to person." The last two phrases make less literal sense, since IM is both one-on-one and person-to-person. A total of 12 responses to this question revolved around the ability of 
instant messaging reference: users' evaluation of library chat Margie Ruppel and Jody Condit Fagan
Reference Services Review

Volume $30 \cdot$ Number $3 \cdot 2002 \cdot 183-197$
Table $X$ Advantages of the traditional desk

Personal

Direct (can physically show where

materials are)

Availability of staff

Quality

Lack of technical difficulties

Speed

No advantages

Total (responses)

Total (respondents)

the staff member to provide direct help. Eight of these mention physically getting up and showing a physical resource, for example, "could actually help you locate a specific book on the shelf" and "physically walk to area to assist in finding material." Most of the other responses are unclear as to whether the direct help is with physical resources or pointing out steps on a screen; the closest language relating to computer help is, "they can come help you with hands on." Five responses mentioned the seemingly perpetual availability of traditional desk staff, for example, "there's always someone at the reference desk to ask for help." Other comments included the quality of interaction ("You can explain your problem better face to face") and the lack of technical difficulties ("somerimes computers can mess up and that's more annoying than having someone just not know").

\section{Disadvantages of traditional reference desk}

The answers to this question are perhaps the most disconcerting in the study, since many of them revolve around unhelpful performance of reference desk staff, including business, lack of ability, unwillingness to help, and unfriendliness (see Table XI). These sentiments echo the findings of Swope and Katzer (1972) and Hernon and Pastine (1977). Of the 51 responses, 32 involved such perceived or actual staff problems. Comments included the following:

The people don't look too friendly.

I have had bad experiences myself. I prefer IM, the people are nicer.

Sometimes they have no clue.
Table XI Disadvantages of traditional reference desk

Staff too busy (actual or perceived) 13

Not anonymous

Staff member not able to help $\quad 10$

Staff member unwilling to help 5

Staff member unfriendly

Inconvenient

No disadvantages

Slow

Total (responses)

Total (respondents)

Some librarians seem put out when you ask them for help.

Lazy, don't think they want to help.

People are busy with other tasks.

You are afraid they are too busy to help.

Morris Library's IM reference staff also works on the physical reference desks. It is impossible to know if this set of staff is, in fact, friendlier and more approachable than other staff, or if it is the removal of the visual element of the desk worker that removes these perceptions.

\section{'... Patrons' high opinions of IM reference were encouraging. For many patrons, IM reference exceeded their expectations. They liked its speed, convenience, and anonymity...'}

A total of 11 responses to this question mentioned the lack of anonymity, with comments such as "I feel embarrassed for asking, its twice as bad because you 'reveal' yourself" and "not anonymous; always have feeling of asking dumb question." Only three responses mentioned the inconvenience of having to go to a desk.

\section{Discussion}

Patrons' high opinions of IM reference were encouraging. For many patrons, IM reference exceeded their expectations. They liked its speed, convenience, and anonymity. Many seemed to be surprised that they actually got helpful answers. The IM reference desk removed the negative assumptions about 
Instant messaging reference: users evaluation of library chat Margie Ruppel and Jody Condit Fagan

reference desk staff that sometimes result from visual perceptions of business, unfriendliness, or disinterest. Seeing no one, patrons assume the IM reference staff person is friendly, knowledgeable, and not busy. Although it is not yet proven that instant messaging completely addresses the reasons for reluctance to ask for help as discussed by Swope and Katzer (1972) and Hernon and Pastine (1977) 30 years ago, it is clear it removes some of the more significant barriers.

'... From the results of this survey, it does not seem that patrons see IM reference as necessarily entailing progress toward an electronic-only library or as a replacement for the traditional desk...'

In addition to removing some of the perceived barriers, IM reference gives staff more of an opportunity for success because the librarian can focus on one patron at a time, and help them as long as needed. IM reference patrons receive undivided attention, which may not always be true at a traditional reference desk. This idea may be a double-edged sword, however, because the pressure to "perform" is heightened by the need to answer quickly and sufficiently:

Users who ask for assistance via chat have high expectations of the service, can be impatient and demanding during the chat, and in general help to create a reference encounter that feels more pressured than is typical at a reference desk (Francoeur, 2001, p. 200).

From the results of this survey, it does not seem that patrons see IM reference as necessarily entailing progress toward an electronic-only library or as a replacement for the traditional desk. Almost all (92 percent) of the survey respondents wanted library staff to tell them about both print and online sources, and many mentioned that they appreciated inlibrary staff to direct them to physical resources. Many of the responses mentioned the face-to-face aspect of the traditional desk to be of benefit.

When considering further development of the IM reference service, patrons were clear about what they want: plenty of staff online weekday evenings. Weekend and weekday afternoons were also desired. They want the system to remain easy to use and would rather see no technical difficulties than "advanced features."

This survey allowed Morris Library staff to discover the benefits and drawbacks of IM reference. It is clearly not a replacement for traditional reference; both traditional and IM reference are necessary at different times for different reasons. For this very reason, some practitioners say the two types of reference should not be compared, but others disagree:

What, if any, comparison should be made to the traditional face-to-face reference services that librarians offer? The case can be made that face-to-face communications and electronic communications are very different forms of communication and should not be compared. In a sense, these two forms of reference service are more complementary than they are duplicative (Sloan, 1998).

On the other hand, at least one study asked respondents to compare the two; a short survey question posed at the University of Buffalo asked users, "Why did you choose IM versus calling, e-mailing, or visiting the library?" (Foley, 2002). Their answers indicated they feel like they:

- should already know the answer;

- wanted instant help;

- did not want to leave their office or home;

- did not want to be put on hold or transferred on the telephone;

- did not want to wait for an e-mail response;

- wanted direct dialect with a human; or

- wanted to be able to continue their Internet connection while talking to library staff (Foley, 2002).

The results of a focus group study published in 1998 say libraries should make a commitment to ongoing user studies and:

Focus on eliminating as many barriers to library use as possible, user-friendly instructional assistance at point-of-need, marketing professional staff and resources, and a commitment to evaluate information provision over instruction (Massey-Burzio, 1998).

In initiating an IM reference service, Morris Library has succeeded in eliminating physical barriers, and, considering the survey results, in providing user-friendly assistance at the 
Instant messaging reference: users' evaluation of library chat Margie Ruppel and Jody Condit Fagan

point-of need. Archer and Cast (1999) talk about point-of-need service:

As any librarian who's been asked a reference question while doing her grocery shopping know, questions no longer just walk up to the Reference Desk. They are in the stacks, across campus, on the other side of town and maybe outside of the country. To continue to serve patrons with different needs, librarians must walk across the library, access the computer screen from across the campus intranet system, answer e-mail and explore other interactive tools for reaching out patrons in a personalized manner.

New library services generally succeed when the "best" aspects of traditional services are incorporated. Transferring effective reference behaviors from the traditional desk environment to the IM service is challenging, given the absence of facial expressions and body language. Gorman (2001) describes the general characteristics of "good" reference librarians as follows:

The ability to put an inquirer at ease, the realization that all questions are important to the questioner, and willingness to help. Combine these with a thorough knowledge of resources and you have the recipe for the "personal relations" of 125 years ago and the reference interview of today.

This is true of reference interviews in both traditional and IM reference situations.

\section{Conclusion}

The survey results indicate that instant messaging is a valid medium for providing reference services that are popular with students. The medium even seems to promise answers to some of the reasons patrons have been reluctant to ask for help for decades, by offering anonymity and quick help without showing the busyness of the librarian on the other end. It is also clear that there are disadvantages to $\mathrm{IM}$ reference, and it will not replace the traditional reference desk in the near future. Library users still want help with physical materials, and explaining the intricacies of database searching are much easier face-to-face. IM reference staff at Morris Library will continue, hopefully, with additional support for evening and weekend hours of service, and for staff to work online

simultaneously.

Future research in this area needs to include an evaluation of staff experiences, an analysis of the conversations themselves, and some kind of contextual study of how electronic reference fits in to the electronic world. At Morris Library, for example, the words typed into IM reference are not dissimilar to those typed into the Web site search. And often, people type into both of these things as if they are searching in a database, on the Internet, or in the online catalog. IM reference may provide insight into patrons' online searching behavior and an opportunity for online bibliographic instruction.

\section{References}

Archer, S.B. and Cast, M. (1999), "'Going where the questions are': using media to maintain personalized contact in reference service in medium-sized academic libraries", The Reference Librarian, No. 65, pp. 39-50.

Calloway, M., Fagan, J., Foes, C. and Ruppel, M. (2001), "Instant messaging reference ... just add librarians", poster session, Illinois Library Association Annual Conference.

Carter, D.S. and Janes, J. (2000), "Unobtrusive data analysis of digital reference questions and service at the Internet Public Library: an exploratory study", Library Trends, Vol. 49 No. 2, pp. 251-65.

Desai, C. and Fagan, J. (2002), "Instant messaging reference", paper presented at Computers in Libraries Annual Conference, Washington, DC, 14 March.

Dewdney, P. and Ross, C.S. (1994), "Flying a light aircraft: reference service evaluation from a user's viewpoint", $R Q$, Vol. 34 No. 2. pp. 217-30.

Durrance, J.C. (1995), "Factors that influence reference success: what makes questioners willing to return?", The Reference Librarian, No. 49/50, pp. 243-65.

Fagan, J. and Calloway, M. (2001), "Creating an instant messaging reference system", Information Technology and Libraries, Vol. 20 No. 4, pp. 202-12.

Fagan, J., Desai, C. and Taylor, M. (2001), "No results found: a library Web site search engine is no substitute for expert help via instant messaging reference", paper presentation at the LITA National Forum, Milwaukee, WI, 12-14 October.

Foley, M. (2002), "instant messaging reference in an academic library: a case study", College and Research Libraries, Vol. 63 No. 1, pp. 36-45.

Francoeur, S. (2001), "An analytical survey of chat reference services", Reference Services Review, Vol. 29 No. 3, pp. 189-203.

Goetsch, L. (1999), Electronic Reference Service: A SPEC Kit, Association of Research Libraries, Washington, DC. 
Instant messaging reference: users' evaluation of library chat Margie Ruppel and Jody Condit Fagan

Gorman, M. (2001), "Values for human-to-human reference", Library Trends, Vol. 50 No. 2, pp. 168-82.

Hatchard, D. and Toy, P. (1986), "The psychological barriers between library users and library staff", Australian Academic and Research Libraries, Vol. 17, pp. 63-9.

Hernon, P. and Pastine, M. (1977), "Students' perceptions of academic librarians", College and Research Libraries, Vol. 38 No. 2 pp. 129-39.

Kibbee, J., Ward, D. and Ma, W. (2002), "Virtual service, real data: results of a pilot study", Reference Services Review, Vol. 30 No. 1, pp. 25-36.

Massey-Burzio, V. (1998), "From the other side of the reference desk: a focus group study", The Journal of Academic Librarianship, Vol. 24 No. 3, pp. 208-15.

Nelson, I. (1991), "Reference - the right way", North Carolina Libraries, Vol. 49, pp. 222-3.

Ross, C.S. and Dewdney, P. (1998), "Negative closure: strategies and counter-strategies in the reference transaction", Reference and User Services Quarterly, Vol. 38 No. 2, pp. 151-63.
Sloan, B. (1998), "Electronic reference service: some suggested guidelines", Reference and User Services Quarterly, Vol. 38 No. 1, pp. 77-81.

Sloan, B. (2002), "Digital reference services bibliography", available at: http://alexia.lis.uiuc.edu/ -b-sloan/ digiref.html (accessed 14 March 2002).

Straw, J.E. (2000), "A virtual understanding: the reference interview and question negotiation in the digital age", Reference \& User Services Quarterly, Vol. 39 No. 4, pp. 376-9.

Swope, M.J. and Katzer, J. (1972), "Why don't they ask questions?", RQ, Vol. 12, pp. 161-6.

Virtual Reference Desk Project (2000), "Facets of quality for digital reference services", The Virtual Reference Desk, available at: www.vrd.org/facets-10-00.shtml (accessed 24 March 2002).

Whelen, D. (2001), "The instant messaging market", American Demographics, Vol. 23 No. 12, pp. 28-31.

(The appendix follows overleaf.) 


\section{Appendix. Extra Credit Assignment: Instant Messaging (IM) Reference Survey}

\section{Extra Credit Assignment, CI 199 Instant Messaging (IM) Reference Survey}

Due: Feb. 20, 2002

This extra credit assignment has two goals:

(1) To introduce students to another way to get library help, instant messaging reference.

(2) To evaluate the instant messaging reference system through a survey instrument

As a part of 2, librarians will be using the survey results in published research. For this portion, all surveys will be anonymous, meaning that after your extra credit is recorded, your name will be removed from the survey data. We are interested in improving our instant messaging reference system and that is what we are going to do with our findings. If you are willing for your data to be used anonymously in our research please sign here:

This information and your signature is required by SIUC's human subjects committee for us to use your survey data in our research. Thanks!

\section{Instant Messaging Reference Survey}

(1) Make sure you signed the front cover letter before proceeding!

(2) Sometime between 1:00 and 4:00 in the afternoon Monday-Friday, try out the Morris Library instant messaging reference service. Visit Morris Library's home page (www.lib.siu.edu) between the mentioned hours and there will be an open text box with the words "Need help?" above it. If the service is busy, keep trying! Try to think of a real question you need help with maybe you need to write an article about a topic for another class, and want to ask how to research in the library on that topic. Chat with the online librarian for at least ten or so lines, to get a good feel for the service.

(3) When you're done, please answer the questions below. You must answer every question to get the extra credit! Do not attach a transcript of the conversation.

How much did you like using the instant messaging system as a way to get help?
(Hated it) 7
6
5
6
3
2
1 (Loved it)

Rate the quality of help that you got from the online librarian
(Terrible) 7
6
5
6
3
2
1 (Loved it)

How frequently do you ask for help at traditional library help desks (in the library building)?
(Never) 7
6
5
6
3
2
1 (Loved it)

If you don't usually ask for help at traditional library help desks, why not? In the second column, check the box if you think it would not be an issue with instant messaging reference:

Reasons why I don't ask at traditional desks (check all that apply):

a. Don't want to have to get up from the computer

b. Person at desk does not look like they want to help or they look too

c. Don't think person at desk will know the answer

d. I feel stupid for not knowing already

e. Don't want to bother going to the library building

Now that you can get help through instant messaging reference, how much do you see yourself increasing or decreasing the number of questions you ask at traditional library help desks? (Circle one.)

Advantages of Instant Messaging:

Disadvantages of Instant Messaging:
Advantages of Traditional Reference Desk:

Disadvantages of Traditional Reference Desk: 
Have you ever used instant messaging (IM) before?

Yes

No

Do you think the speed of the system is sufficient?

Yes

No

Do you think the library staff responds quickly?

Yes

No

Would you use instant messaging reference service again?

Yes

No

When you use online reference, do you expect to get referred to answers you can find online (e.g. Web sites, online journals)?

Yes

No

When using instant messaging reference, do you want library staff to tell you about both print and online sources or just online sources?

Print and Online

Just Online

What days/hours would be the best times to have this service available? (Circle up to three choices.)

Weekday Mornings Weekday Afternoons

Weekday Evenings

Weekend Mornings

Weekend Afternoons

Weekend Evenings

Was this service different from what you expected when you entered your question?

Yes No

If Yes, How?

What features would you add to this service? (List some.) 